\title{
GESTÃO DE PROJETOS ATRAVÉS DO DMAIC: UM ESTUDO DE CASO NA INDÚSTRIA AUTOMOTIVA
}

\section{MANAGEMENT OF PROJECTS THROUGH DMAIC: A CASE STUDY IN THE AUTOMOTIVE INDUSTRY}

\author{
Marcelo Gechele Cleto*mgcleto@ufpr.br \\ Leandro Quinteiro** quinteirofr@yahoo.br \\ *Universidade Federal do Paraná - PPGEP/UFPr \\ ${ }^{* *}$ Profissional da Indústria Automotiva
}

\begin{abstract}
Resumo: A gestão de projetos nas grandes empresas é uma atividade de elevada importância, pois torna possível a implementação de decisões que normalmente abrangem diversas áreas e demandam significativo volume de recursos. Este trabalho objetiva apresentar a aplicação da metodologia de gestão de projetos DMAIC, proposta pelo Método Seis Sigma para solução de problemas em uma empresa industrial de grande porte. Após a revisão bibliográfica é apresentado um Estudo de Caso na indústria automotiva, no qual é descrita a aplicação da metodologia e verificados seus resultados preliminares. Conclui-se que a utilização da metodologia DMAIC foi importante para a adoção de uma abordagem científica estruturada na condução do projeto, ficando confirmada a sua robustez e possibilitando ao projeto alcançar seus objetivos de uma forma organizada, multidisciplinar e econômica.
\end{abstract}

Palavras-chave: Gestão de projetos. DMAIC. Solução de problemas. Seis sigma. Indústria automotiva.

\begin{abstract}
The management of projects in big companies is an activity of high level of importance. This is because they make possible the decisions implementation those normally affect several areas and demand significant level of resources. This work presents a DMAIC projects management methodology application, proposed by Six Sigma Method for problems solution in a large size industrial company. After the bibliographical review it is presented a Case Study in the automotive industry, in what it is described the methodology application and verified its preliminary results. The conclusion is that the use of the DMAIC methodology was important to the adoption of a scientific structured approach in the project. Its robustness was confirmed and it made possible for the project to achieve its goals in an organized, multi-disciplinary and economic way.
\end{abstract}

Key-words: Project management. DMAIC. Problems solution. Six sigma. Automotive industry.

\section{INTRODUÇÃO}

Em virtude da complexidade existente nas operações de empresas industriais de grande porte, que contam com a dependência de fornecedores localizados no próprio país e no exterior ao longo de sua cadeia produtiva, muitas destas empresas 
defrontam-se com problemas de qualidade, logística, produção, etc., que necessitam envolver várias áreas da empresa para a sua solução. Assim, ao constatar-se um problema de qualidade de um componente ou produto entregue por um fornecedor, um projeto multifuncional deve ser estabelecido, de modo a observarem-se as diversas facetas do problema e propor-se uma solução que atenda os requisitos existentes nas áreas envolvidas. A fim de realizar-se um trabalho eficaz e produtivo, é importante que seja usado um método confiável, que já tenha sido testado de maneira empírica na organização, de modo a obter-se uma solução permanente para o problema em questão. A metodologia DMAIC, proposta pelo método Seis Sigma é uma alternativa de metodologia para esta situação. Ela possibilita uma abordagem científica, estruturada e flexível para ser aplicada em um ambiente empresarial de empresas de grande porte.

\section{O MÉTODO SEIS SIGMA}

Em virtude das exigências cada vez maiores em termos de qualidade e produtividade a que estava sujeita no final da década de 80 , a Motorola Inc. (com matriz nos EUA) inicia a utilização de um método de trabalho para melhoria de seus produtos e processos, que passa a denominar de Seis Sigma. Este método trouxe ganhos elevados e prêmios de qualidade à empresa, o que estimulou outras empresas a adotarem-no, como a General Electric - o caso de maior notoriedade na aplicação do Seis Sigma, a Sony, a Asea Brown Boveri (ABB), entre outras (BAÑUELAS; ANTONY, 2002). No Brasil, o Seis Sigma foi disseminado a partir de 1997 através da sua utilização pelo Grupo Brasmotor, que alcançou resultados expressivos em 1999 (WERKEMA, 2002). Estudos recentes mostram que empresas que adotaram programas de qualidade, como o Seis Sigma, tiveram grande sucesso tanto em termos de seus indicadores de qualidade como em relação ao retorno do investimento (CARVALHO et al., 2008).

O nome Seis Sigma é uma referência à letra Sigma " $\sigma$ " do alfabeto grego, que representa o desvio-padrão de uma distribuição normal de valores ou medidas. O método é bastante quantitativo e busca a redução da variabilidade dos processos, alcançando um nível de defeitos muito próximo do zero. Alcançar-se o Seis Sigma significa que o processo produz 3,4 peças com defeitos por milhão de peças 
produzidas. Um nível tão alto de qualidade leva a empresa a ser a melhor, a referência ou o benchmark (detentor das melhores práticas) no ramo em que atua.

O método ou programa Seis Sigma sustenta-se graças a uma correta seleção dos projetos que a empresa irá tratar internamente, sendo o passo inicial para isto a compreensão das características críticas para a qualidade. Também Fernandes e Turrioni (2007) colocam que a seleção do projeto é crucial para o sucesso do programa Seis Sigma a ser implantado na organização. Posteriormente, deve-se escolher um dos métodos de solução de problemas que possam ser aplicados no programa (LYNCH et al., 2003). Alguns deles são: a) M-PCpS (machine-process characterization study), que é um estudo para a caracterização e otimização de processos, e que visa eliminar perda de tempo e dinheiro; b) DFSS (design for Six Sigma);c) DMADV, que contempla as fases definir, medir, analisar, desenhar e verificar; d) DMEDI, com as etapas definir, medir, explorar, desenvolver e implementar; e) DMAIC, composto pelas etapas: define (definir), measure (medir), analyse (analisar), improve (melhorar) e control (controlar). Destes métodos o mais utilizado atualmente é o DMAIC, uma vez que é composto de cinco etapas que possibilitam uma adequada organização da implantação, desenvolvimento e conclusão da maior parte dos projetos Seis Sigma (ANDRIETTA;MIGUEL,2007).

Deve-se notar que existem outros métodos para solução de problemas no âmbito organizacional. Paris (2003) apresenta uma análise de quatro deles: a) MASP - Metodologia de Análise e Solução de Problemas, proposta por Y. Ando; b) Método das 8 Disciplinas (ou 8-D), idealizado pela Ford Motors Company; c) Método KT , proposto por Kepner e Tregoe; e d) QC - Story (ou Quality Control Story), apresentado por Vicente Falconi Campos e baseado no Controle da Qualidade Total no Estilo Japonês.

Desta forma, a implantação de um Projeto Seis Sigma conta com a escolha e utilização de um método adequado de solução de problemas (o DMAIC) e também de técnicas e ferramentas que serão utilizadas para obter, tratar e analisar as informações. As mais utilizadas tem sido: Coleta de Dados, Histograma, Diagrama de Pareto, Brainstorming, Cartas de Controle, Índices de Capacidade, Fluxograma, Mapeamento do Processo, Avaliação de Sistema de Medição e CEP - Controle Estatístico de Processo (ANDRIETTA;MIGUEL,2007). 
O método Seis Sigma utiliza uma terminologia específica para denominar seus profissionais, tais como responsável (sponsor), facilitador, campeão (champion), cinturão preto (black belt), cinturão verde (green belt), cinturão amarelo (yellow belt) e cinturão branco (white belt) (WERKEMA, 2002). Neste trabalho não foi utilizada esta terminologia por esta não ter sido utilizada na condução do projeto apresentado no Estudo de Caso.

\section{A METODOLOGIA DMAIC}

Um projeto que utiliza a metodologia DMAIC deve se referir a um problema de desempenho organizacional, o qual tem uma solução desconhecida. Deve haver um conjunto de objetivos mensuráveis ligados a um conjunto de indicadores bem definidos e que correspondam à oportunidade de solução, dentro de uma perspectiva de melhoria contínua. O progresso do projeto deve ser acompanhado através de indicadores e este deve culminar em benefícios de custo, tempo ou qualidade. Normalmente, sugere-se que o projeto deve ser realizado em um período de 6 a 12 meses dependendo do seu porte, do engajamento da empresa e dos recursos alocados a este. Normalmente os tempos estimados de duração das etapas do DMAIC são: Etapa D - 2\%, Etapa M - 25\%, Etapa A - 45\%, Etapa I $25 \%$ e Etapa C - 3\%.

A metodologia de solução de problemas DMAIC é um conjunto ordenado de etapas. Ao constituir-se um grupo de trabalho e avançar-se na solução do problema as várias atividades realizadas começam a se complementar e informações valiosas surgem, com o grupo ganhando confiança de que a solução do problema será efetivamente alcançada. As etapas do DMAIC e seu conteúdo resumido são apresentadas a seguir (GUPTA, 2005; FRANZ, 2003). Não será considerada a etapa incluída após uma revisão do método, que incluiu o Reporting - R (SENAPATI, 2004).

Pré-Estudo: identificam-se informações relevantes para o início do projeto, tais como: problema a ser abordado, oportunidades e ameaças existentes, áreas envolvidas e equipe que trabalhará no projeto;

D - Define (Definir): define-se com precisão o escopo do projeto;

M - Measure (Medir): determina-se a localização ou foco do problema; 
A - Analyse (Analisar): determinam-se as causas de cada problema prioritário;

I - Improve (Melhorar e Implementar): propõem-se, avaliam-se e implementam-se soluções para cada problema prioritário;

C - Control (Controlar): garante-se que o alcance da meta seja mantido no longo prazo.

A seguir serão apresentadas algumas atividades componentes e questões utilizadas para facilitar a implementação das fases apresentadas acima. Estão baseadas: a) na bibliografia consultada; b) em documentos internos desenvolvidos pela empresa utilizada como estudo de caso, os quais foram consolidados através de diversas aplicações do DMAIC por um período de 3 anos anterior ao projeto aqui descrito.

\subsection{Pré-estudo:}

Nesta fase toma-se o primeiro contato com o problema na forma de um projeto multifuncional estabelecido pela empresa. As seguintes perguntas deverão ser respondidas:

a) De forma preliminar, qual é problema que deve ser resolvido?

b) De forma preliminar, quais as oportunidades e ameaças para o negócio da empresa?

c) O que acontecerá se não for feito nada a respeito?

d) Que áreas são interessadas e afetadas pelo projeto?

e) Como será organizado e conduzido o projeto na organização?

Tais informações deverão estar organizadas em um documento denominado CONTRATO. Ver Modelo de Contrato no Anexo 1.

\subsection{Fase Define:}

Nesta fase sugere-se a construção de um Business Case, isto é, um Caso de Negócio, que deverá estabelecer as diretrizes para a formação do grupo de trabalho e desenvolvimento do projeto. As questões inicialmente colocadas no Pré-Estudo devem agora ser debatidas novamente e respondidas com maior segurança pelo 
grupo de trabalho. Deverão ser respondidas as seguintes questões ou ações executadas:

a) Revisar qual o problema (resultado indesejável ou oportunidade detectada) a ser abordado no projeto.Este deverá constar no CONTRATO;

b) Revisar a conexão estratégica do projeto com o negócio. Deverá constar no CONTRATO e no documento VOC (Voice of Customer). Ver Modelo no Anexo 1;

c) Entender o processo das necessidades dos clientes através do VOC;

d) Definir o processo a ser melhorado (quem são os clientes, fornecedores, entradas e saídas do processo).Através do CONTRATO e do SIPOC (Supplier-Input-Process-Output-Customer). Ver Modelo no Anexo 1.

e) Definir os indicadores (Key Performance Indicators) que irão evidenciar o impacto da mudança. Através do CONTRATO;

f) Identificar qual é o impacto econômico e retorno que este projeto dará à empresa?

g) Identificar qual o objetivo a ser alcançado?

h) Definir Cronograma inicial do projeto.

i) Definir fronteiras e restrições ao projeto.

j) Aprovar o CONTRATO pelo Comitê Diretor do Projeto.

\subsection{Fase Measure:}

Uma vez respondidas as perguntas componentes da fase anterior, surge naturalmente para o grupo de trabalho uma demanda maior de informações, de modo a aprofundar o que foi descrito e poder-se medir os processos envolvidos com maior detalhamento.

As seguintes questões devem ser respondidas ou ações executadas:

a) Descrever o processo atual utilizando o Mapeamento do Fluxo de Valor, conforme Shook e Rother (1998);

b) Identificar e selecionar características do processo através dos indicadores obtidos no mapeamento;

c) Validar os sistemas de medição das características selecionadas; 
d) Identificar todos os desperdícios no processo;

e) Identificar pequenas oportunidades de melhoria no processo;

f) Registrar o desempenho atual do processo de forma a identificar curvas de tendência;

g) Revisar benefícios financeiros em função da medição do desempenho;

h) Revisar o CONTRATO, ajustando o foco do projeto e revendo metas e objetivos.

\subsection{Fase Analyse:}

Nesta fase o processo principal relativo ao problema abordado no projeto já foi identificado e medido através de um conjunto de indicadores. Passa-se, então, à fase de análise das informações, visando-se determinar as causas fundamentais do problema identificado. Novamente algumas perguntas devem ser respondidas ou ações executadas. São elas:

a) Desenvolver uma síntese do Estado Atual do processo, baseado na interpretação das medidas realizadas e suas variações;

b) Quais são os efeitos gerados a partir do desempenho atual do sistema?

c) Quais as hipóteses de causa-raiz do problema estudado?

d) Realizar um brainstorming para levantar uma lista de causas potenciais;

e) Coletar e validar as evidências das hipóteses (através de testes, estudos, gráficos, análises, etc.);

f) Existem informações a respeito de processos semelhantes ao processo atual e soluções potenciais (Benchmarking)?

g) Verificar se ramificações ou variantes do projeto podem afetar (positivamente ou negativamente) outros processos;

h) Elevar o nível de conhecimento através dos dados coletados e ajustar o foco de análise ou o problema, se necessário;

i) Desenvolver melhorias identificadas através de Kaizens rápidos utilizando PDCA's, confome Campos (1992);

j) Definir cenários ou hipóteses a serem desenvolvidas na fase do Improve;

k) Apresentar necessidade de recursos para aprovação;

l) Revisar o CONTRATO, através de suas metas e objetivos. 


\subsection{Fase Improve:}

Nesta fase serão realizadas atividades para gerar idéias que levem à solução do problema e também à implantação ou teste destas idéias. Algumas perguntas devem ser respondidas ou ações executadas são:

\section{Sub-fase DECISION (DECISÃO):}
a) Verificar a eficiência da implementação dos kaizens rápidos;
b) Quais as idéias para soluções potenciais ?
c) Avaliar, selecionar e otimizar as melhores soluções;
d) Avaliar e reduzir os riscos relativos à solução escolhida;
e) Qual o impacto local e global da solução escolhida ?
f) Submeter as soluções potenciais à aprovação;

\section{Sub-fase IMPLEMENTATION (IMPLEMENTAÇÃO):}

g) Projetar um piloto, ou seja, um teste prático da solução proposta;

h) Ajustar o mapa futuro de acordo com o piloto;

i) Elaborar um plano detalhado para implementar a solução de uma maneira ampla (inclusive assegurando recursos);

j) Aprovar a proposta de implementação de maneira ampla;

k) Confirmar a eficiência da solução de uma maneira ampla;

I) Preparar treinamento operacional;

m) Modificar parâmetros de qualidade de acordo com as mudanças;

n) Identificar e modificar as novas normas, padrões e instruções de trabalho.

\subsection{Fase Control:}

Nesta fase ocorre a avaliação do alcance do objetivo do projeto no longo prazo. Os resultados obtidos após a implementação das soluções em larga escala devem ser monitorados para a confirmação da solução do problema de uma forma permanente. Utiliza-se para isto um conjunto de ferramentas, tais como sistemas de medição e inspeção, diagrama de Paretto, carta de controle, histograma, etc.. 
Caso o resultado da avaliação não seja favorável, deve-se retornar à fase do Measure, para verificar-se se houve algum problema ou falha na definição ou medição dos indicadores. Procede-se novamente às fases do Analyse e Improve. Se o resultado da avaliação for positivo, ou seja, o objetivo foi atingido em larga escala, parte-se para a padronização das alterações realizadas no processo em virtude das soluções adotadas.

Algumas perguntas devem ser respondidas ou ações executadas. São elas:

a) Quais são os riscos do novo processo (após a implementação das melhorias)?

b) Identificar os controles associados com os maiores riscos do novo processo.

c) Fazer uma análise crítica das ações, indicadores e da nova realidade;

d) Confirmar os ganhos com a alteração;

e) Validar o alcance dos objetivos do projeto;

f) Concluir o projeto ou revisar as fases Analyse ou Improve;

g) Registrar e padronizar a melhoria;

h) Preparar apresentação final com a presença das partes interessadas;

i) Requerer aprovação final do projeto;

j) Identificar novas oportunidades de projetos achadas no decorrer do projeto atual;

k) Registrar lições aprendidas;

l) Registrar o projeto nos sistemas apropriados e passar suas conclusões para a organização.

\subsection{Auditorias:}

As auditorias realizadas para autorizar as passagens entre as etapas do método DMAIC são um instrumento importante para a garantia de que foram executadas as atividades previstas. Tais auditorias trazem um grande benefício ao Coordenador e Grupo de Trabalho na condução do projeto, pois contam com alguém de fora olhando o projeto, com isenção, mas interesse de que alcance seus objetivos. Também a Diretoria ou Gerência envolvidas tem interesse na realização das auditorias, pois, com isto têm uma maior garantia de que um método científico 
está sendo utilizado para resolver o problema. A informação de que o projeto foi aprovado por um Auditor para uma nova etapa demonstra que seus requisitos básicos foram atendidos. No entanto, a simples auditoria das atividades previstas nas etapas do DMAIC não garante por si só, que o projeto está sendo bem conduzido e que alcançará os objetivos previstos. As atividades constantes das etapas podem ser realizadas com um nível variável de profundidade, em função de recursos disponíveis (humanos, financeiros e organizacionais), prazo de término previsto, situações imprevistas, alterações de volumes e produtos, etc.. A auditoria, de um modo geral, mostrará indícios de que o problema foi ou não bem definido, que os indicadores são ou não adequados à situação ou outra evidência qualquer.

Normalmente, os resultados da auditoria das fases de um projeto podem ser: APROVADA, APROVADA COM PENDÊNCIAS (Hard Points) e NÃO APROVADA (Gate Stopper). Na APROVADA COM PENDÊNCIAS devem ser listadas pelo auditor as pendências e a data prevista para a sua nova apresentação com as pendências resolvidas. Nas grandes empresas há um setor normalmente ligado à área da Gestão da Qualidade que conta com os profissionais auditores. Durante as auditorias estes devem ter uma postura positiva em relação ao andamento do projeto, entendendo as dificuldades encontradas pelo Grupo de Trabalho e Coordenador, principalmente nas primeiras etapas do projeto, quando este ainda não está fluindo com facilidade, o que acontece com mais facilidade nas etapas seguintes.

\section{ESTUDO DE CASO - INDÚSTRIA AUTOMOTIVA}

A abordagem do Estudo de Caso foi utilizada em função de possibilitar um aprofundamento da investigação das decisões, ações e desdobramentos relativos ao projeto em questão. Yin (2005) realça os fatores positivos desta abordagem, quando se tem informações disponíveis para se tomar conclusões relevantes sobre o tema em estudo. Kumar \& Sosnoski (2009) também apresentam um exemplo de aplicação do DMAIC para a obtenção de melhorias sistemáticas de qualidade e custos no chão de fábrica.

Os autores deste trabalho desempenharam as funções de Coordenador do Projeto, Profissional Especialista em DMAIC e Consultor Externo ao Projeto. Na 
obtenção das informações foram utilizadas as seguintes técnicas de pesquisa, descritas por Lakatos e Marconi (2009): documentação direta e indireta, observação participante, entrevista e questionário.

Será apresentado um Estudo de Caso referente a uma empresa de grande porte do setor automotivo, aqui chamada de Empresa $A$, a qual adotou a metodologia do DMAIC para resolver um problema relativo à qualidade de peças de um de seus fornecedores. As peças fabricadas pelo referido fornecedor, aqui denominado de Empresa B, tinham uma elevada importância no aspecto visual do produto acabado e, portanto, não podiam ser aceitas com qualidade superficial abaixo do nível mínimo exigido pela empresa A. Ver na Fig. 1 o fluxo de produção através da Empresa $\mathrm{A}$.

Além da questão da qualidade das peças também o aspecto logístico era relevante para a estabilização do processo de pintura que se realizava na Empresa A, uma vez que atrasos e re-trabalhos sobre as peças entregues redundavam em grande perda de tempo e despesas. Os padrões de qualidade da empresa A são bastante rigorosos e o seu atendimento requerem um efetivo engajamento do fornecedor. Este Estudo de Caso descreve as definições e ações tomadas pela Coordenação e Grupo de Trabalho que esteve à frente do projeto no período de Fevereiro de 2008 a Janeiro de 2009 (12 meses).

$\begin{aligned} & \text { Recebim. das } \\ & \begin{array}{l}\text { Peças Brutas } \\ \text { P.A. }\end{array} \\ & \begin{array}{l}\text { do Fornecedor } \\ \text { (Empresa B) }\end{array}\end{aligned}$ na Empreşão $\rightarrow$ Pintura das Peças $\rightarrow$ Inspeção $\quad$ na Empresa A $\quad$ na Empresa A $\rightarrow$ Rejeição das Peças

Figura 1- Esquema simplificado do fluxo de produção dos produtos da Empresa $A$.

\subsection{Origem do Problema}

Em um passado recente, a empresa $A$, filial de multinacional estrangeira, localizada no Brasil, tinha a definição de comprar peças com desenho e processo de fabricação complexos de um fornecedor localizado no exterior. Grande fabricante das peças e conhecedor da tecnologia de fabricação requerida, tal fabricante garantia a qualidade nos níveis requeridos pela empresa A. A localização de um 
fornecedor no exterior, no entanto, traz uma série de transtornos ao fluxo de operações de uma empresa industrial de veículos localizada, por exemplo, no Brasil. Um longo período de tempo para a entrega, estoques elevados, pressões sobre os custos em função da variação do câmbio, estímulos governamentais para a fabricação no próprio país, entre outras razões, estimulam as grandes empresas a nacionalizar a produção de determinados conjuntos e peças.

No entanto, a decisão a respeito da transferência da produção de peças e componentes complexos de um fornecedor para outro não é um processo simples, uma vez que envolve a transferência de moldes, matrizes e outros equipamentos normalmente de propriedade da empresa que utiliza tais peças ou componentes em seu produto acabado, para o novo fornecedor escolhido. Tal relacionamento, normalmente estabelecido para uma longa duração, exige um grau elevado de confiança e comprometimento de ambas as partes, de forma que sejam atingidas as metas comuns de qualidade, entrega e custo.

Para fazer frente a esta situação, isto é, da mudança de fornecedor no exterior para outro instalado no Brasil, a Empresa A contatou possíveis fornecedores internos, e selecionou um deles (Empresa B), que em um primeiro período atendeu plenamente os padrões de qualidade requeridos.

Após este primeiro período, de cerca de 03 meses, no entanto, iniciou-se uma grande instabilidade na qualidade das peças entregues pela empresa $B$, tornando-se tal fato um problema crônico para a empresa $A$, uma vez que as constantes promessas e ações desencadeadas pela empresa $B$ não traziam os resultados esperados e o risco de parada da linha de montagem da Empresa A ficava iminente.

Em função da falta de confiança na entrega das peças com a qualidade requerida pela empresa $B$, a empresa $A$ passou a realizar pedidos de peças à antiga fornecedora localizada no exterior, em caráter excepcional, pois a elevados custo e prazo de entrega. A empresa $B$, também filial de uma multinacional estrangeira, passou no período relatado neste caso por uma grande reformulação de sua estrutura administrativa na matriz e no Brasil, como a troca da diretoria, dos corpos gerencial e técnico, etc., o que impactou fortemente na estabilidade das entregas para a Empresa A. 


\subsection{Adoção da Metodologia DMAIC}

A disposição da Empresa $A$ ao surgirem as primeiras evidências de que os problemas com a qualidade das peças da empresa $B$ não seriam resolvidos rapidamente, foi estabelecer um Grupo de Trabalho e um Coordenador, os quais pudessem de uma maneira preventiva avaliar o que tinha ocorrido, estava ocorrendo e de uma maneira pro-ativa, pudessem sugerir alterações na forma como a própria Empresa $A$ tinha se conduzido em todo o processo, de forma a impedir que situações como esta viessem a acontecer novamente.

A discussão do problema entre os envolvidos proporcionou a criação de um Grupo de Trabalho composto de profissionais oriundos de várias áreas da Empresa A, tais como Manufatura (1), Pintura (1), Logística (1), Compras (1), Engenharia de Produto (1), Especialista na Metodologia DMAIC (1) e Suporte Técnico (1). O coordenador ou líder do projeto foi contratado especificamente para este, na condição de consultor externo. Desta forma, oficialmente iniciou-se o projeto com 8 profissionais.

O objetivo preliminar do projeto foi identificar um conjunto de ações a serem adotadas ou incorporadas nas rotinas internas da Empresa $A$ que pudessem reduzir ao máximo o risco de ocorrência de uma situação semelhante à ocorrida com a Empresa B. Portanto, buscava resolver o problema de maneira definitiva na organização. A metodologia DMAIC era uma metodologia que já estava sendo utilizada em outros projetos da Empresa A. Havia, portanto, conhecimento teórico e prático, para a sua adoção. Deve-se notar que na Empresa $A$ há uma área estruturada para dar suporte aos projetos onde é adotado o DMAIC, como metodologia de gestão de projetos.

A seguir serão apresentadas as ações e decisões tomadas pelo Coordenador e Grupo de Trabalho do Projeto em relação a cada uma das fases do DMAIC, conforme apresentadas no item 3. 


\subsection{Pré-Estudo:}

Como decisão da Diretoria da Empresa A, foi estabelecido um Coordenador (ou Líder do Projeto) e um Grupo de Trabalho, apresentados no Organograma a seguir para a implantação do projeto. Ver Fig. 2.

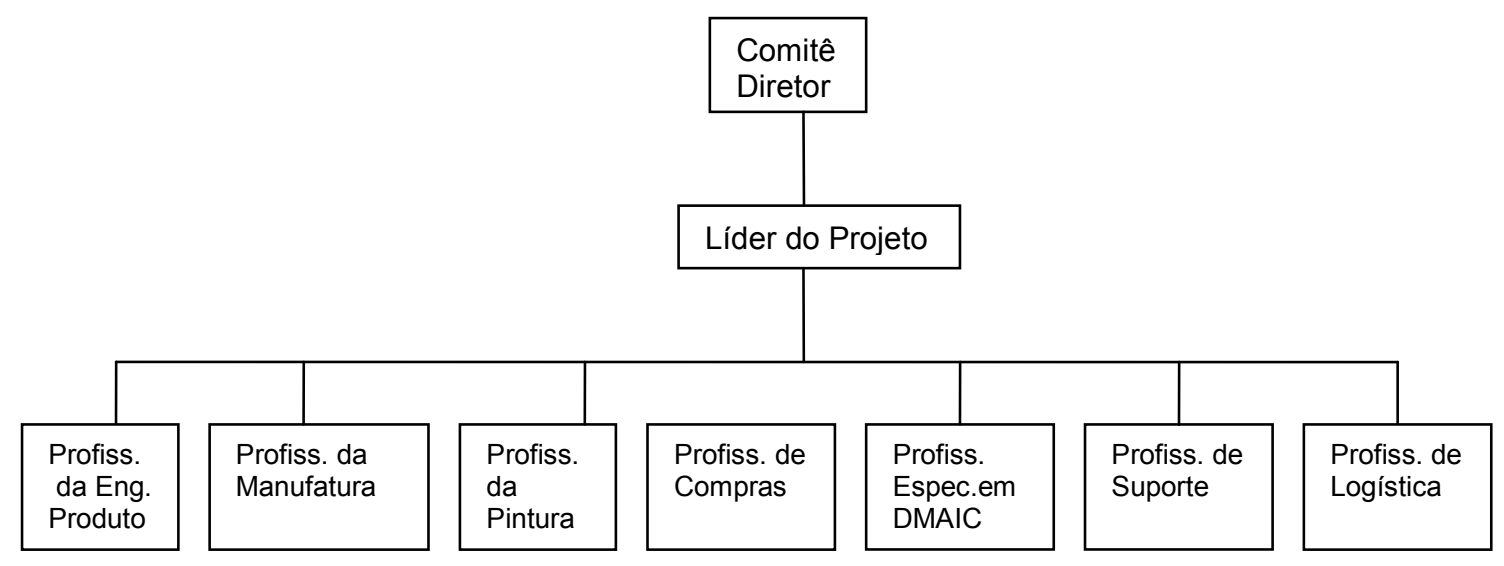

Figura 2 - Organograma relativo ao projeto.

Uma das primeiras ações tomadas pelo Coordenador, antes de iniciarem-se as reuniões do Grupo de Trabalho, foram entrevistas individuais com os membros do Grupo de Trabalho, com o preenchimento por escrito das respostas a um questionário.

O objetivo desta investigação inicial foi obter-se a visão de cada um dos futuros participantes do projeto a respeito do problema que estavam vivenciando em suas respectivas áreas. As perguntas submetidas a 05 profissionais da empresa $A$, bem como suas respostas, estão listadas no Quadro 1 a seguir. Os profissionais Especialista em DMAIC e de Suporte não participaram desta atividade. 


\begin{tabular}{|c|c|}
\hline Perguntas & Respostas \\
\hline $\begin{array}{l}\text { 1)Por que este projeto está } \\
\text { sendo implantado? }\end{array}$ & $\begin{array}{l}\text { Situação de insatisfação crônica com fornecedor e com áreas internas da Empresa A; } \\
\text { distúrbios no processo de nacionalização de fornecedores; problemas de qualidade, prazos, } \\
\text { custos; comprometimento de capacidade e entrega de produtos acabados. }\end{array}$ \\
\hline $\begin{array}{l}\text { 2)Quais as causas principais } \\
\text { dos resultados atuais? }\end{array}$ & $\begin{array}{l}\text { Peças faltantes; baixa qualidade; lote de introdução muito pequeno; falta de controle do } \\
\text { processo fabril do fornecedor; processo de desenvolvimento de peças não segue padrões } \\
\text { existentes na Empresa A. }\end{array}$ \\
\hline $\begin{array}{l}\text { 3)Como pode ser modificada } \\
\text { a situação atual em relação a } \\
\text { aspectos técnicos, comerciais } \\
\text { e à integração entre áreas? }\end{array}$ & $\begin{array}{l}\text { Alterações profundas do processo no fornecedor e seu maior envolvimento com a solução; } \\
\text { acesso ao fornecedor para busca de soluções; substituição da tecnologia atual; necessidade } \\
\text { de maior integração entre as áreas de A envolvidas; critérios de aceitação de peças mais } \\
\text { objetivos; revisão geral da cadeia de custos e impactos da situação atual; utilização de } \\
\text { metodologia robusta para condução da modificação da situação. }\end{array}$ \\
\hline $\begin{array}{l}\text { 4) As entregas atuais de seu } \\
\text { trabalho estão claras para os } \\
\text { demais envolvidos (outras } \\
\text { áreas)? Por que? }\end{array}$ & $\begin{array}{l}\text { Alguns acham que sim, outros razoavelmente; as responsabilidades estão claras, mas houve } \\
\text { falhas no processo de nacionalização. }\end{array}$ \\
\hline $\begin{array}{l}\text { 5) As entregas do projeto } \\
\text { proposto (ver descrição } \\
\text { adiante) levarão à melhorias? } \\
\text { Por que? Quais as } \\
\text { dificuldades envolvidas? }\end{array}$ & $\begin{array}{l}\text { "Sim" foi a resposta mais freqüente; utilizando-se uma metodologia as chances de sucesso } \\
\text { do projeto são grandes; dificuldades: tempo disponível ao projeto, aceitação de mudanças } \\
\text { que tornem o processo de nacionalização mais formal e lento. }\end{array}$ \\
\hline $\begin{array}{l}\text { 6) Quais as condições } \\
\text { necessárias para que isto } \\
\text { aconteça (alteração efetiva da } \\
\text { situação atual)? }\end{array}$ & $\begin{array}{l}\text { Seguir padrões, rotinas e procedimentos existentes em A; maior envolvimento do fornecedor; } \\
\text { acompanhamento das várias etapas do processo de desenvolv. no fornecedor e na Empresa } \\
\text { A; melhor integração e comunicação entre áreas da Empresa A e com o fornecedor; } \\
\text { liberdade na Empresa A para adoção de outros materiais e processos produtivos; adoção } \\
\text { disciplinada de uma metodologia robusta. }\end{array}$ \\
\hline $\begin{array}{l}\text { 7)Quanto tempo você } \\
\text { considera necessário para a } \\
\text { realização de um projeto que } \\
\text { elimine os problemas atuais } \\
\text { de forma permanente? }\end{array}$ & $\begin{array}{l}\text { De } 6 \text { a } 8 \text { meses (1 vez); } 12 \text { meses ( } 2 \text { vezes); Mín de } 6 \text { meses ( } 2 \text { vezes). } \\
\text { O período final de duração do projeto foi de } 12 \text { meses. }\end{array}$ \\
\hline $\begin{array}{l}\text { 8)Que ações } \\
\text { fundamentais considera } \\
\text { eliminação dos pra a } \\
\text { atuais de forma permanente? }\end{array}$ & $\begin{array}{l}\text { Criar projeto de nacionalização ou outro adotando os procedimentos existentes (foruns de } \\
\text { tomada de decisão, etapas e condições para o projeto ir em frente, auditorias, etc.); } \\
\text { avaliação de riscos da nacionalização mais cuidadosa; uso de método objetivo; estabelecer } \\
\text { coordenador neutro; consciência da alta administração para sua necessidade. }\end{array}$ \\
\hline
\end{tabular}

Quadro 1 - Questões submetidas aos membros do Grupo de Trabalho (2 meses antes do início efetivo das atividades do projeto) e suas respostas.

Fonte: Grupo de Trabalho. Período: 01/12/07 a 31/01/08.

Nesta etapa estabelecidas pela Gerência e consideradas relevantes para a solução dos problemas as seguintes Entregas (resultados esperados do projeto) preliminares do projeto:
a) etapas e critérios a serem considerados em cada uma das fases de desenvolvimento da peça, fornecimento, industrialização e pintura dos componentes;


b) identificação dos fatores condicionadores a serem verificados para avanço nas etapas do processo, tais como rotinas padronizadas, checklists, etc.;

c) definição das condições de processo para atendimento aos níveis de qualidade e volumes de produção indicados;

\section{Organização e andamento do Projeto:}

Inicialmente, o projeto foi desenvolvido com um cronograma de reuniões semanais com duração de $2 \mathrm{~h}$, por um período de 6 meses. Nestes primeiros 6 meses o Coordenador foi um profissional externo à Empresa A. Após este período, por mais 6 meses, a coordenação do projeto passou para um profissional da própria Empresa A, passando o primeiro Coordenador a cumprir uma função de assessoria ao projeto, durante os 03 primeiros meses. O projeto totalizou 12 meses.

A carga de trabalho do primeiro Coordenador (nos 06 primeiros meses) foi inicialmente de $8 \mathrm{~h}$ semanais, envolvendo além das reuniões, a realização de contatos individuais nas várias áreas da Empresa $A$ envolvidas, trabalhos de busca, esclarecimento e organização de informações, de forma que fossem úteis ao projeto.

Nos últimos seis meses a carga-horária do segundo Coordenador dedicada ao projeto foi de $4 \mathrm{~h}$ semanais.

O suporte em relação à metodologia DMAIC foi fornecido por profissional especialista e experiente na sua utilização. Foi justamente este profissional que passou a ser o Coordenador do Grupo de Trabalho na segunda etapa do projeto. Já nas primeiras reuniões tomou-se a providência de estabelecer-se um local virtual na intra-net da Empresa A para a colocação dos arquivos que fossem sendo gerados, recebidos e utilizados para acompanhamento do andamento dos trabalhos pela equipe, denominado de Team-place (Local do time).

\subsection{Fase Define:}

Serão apresentadas ações desenvolvidas e informações coletadas de modo que as perguntas apresentadas no item 3.2 pudessem ser respondidas. São elas: 
a) Importância do projeto para o negócio: vários retrabalhos, causando perda da capacidade e atrasos no processo de pintura, bem como necessidade de horas-extras na Empresa A. Com a melhoria da qualidade será possível um aumento da capacidade de pintura da Empresa A. Outra consequência do projeto será uma maior integração entre áreas da Empresa $A$ e entre seus indicadores;

b) Importância do projeto para o negócio (não se fazendo nada): novos projetos terão os mesmos problemas, capacidade de produção continuará ameaçada, entrega no prazo ameaçada, dependência de fornecedores que não satisfazem os requisitos da Empresa $A$, desmotivação do pessoal em função da inexistência de melhoria da qualidade, permanência de conflitos entre áreas, afetando os indicadores, menor lucratividade e imagem da Empresa A afetada.

c) Indicadores: Estes indicadores foram escolhidos em virtude de possibilitarem a visualização e monitoramento dos principais processos envolvidos no trabalho. a) PPM (Partes Por Milhão); b) Percentagem de Rejeições em relação à Produção; c) Veículos retirados da Linha de Montagem em virtude de peças defeituosas; d) Precisão da entrega; e) Custo de re-trabalho. Foram apresentados no documento da Empresa A denominado CONTRATO os valores dos indicadores no momento da realização da fase DEFINE e também os valores destes indicadores colocados como objetivos a serem alcançados até o final do projeto.

\section{d) Restrições:}

Fronteira: Foco do projeto de acordo com o escopo. Foi utilizado aqui o Diagrama SIPOC (Supplier-Input-Process-Output-Customer). Também foi definido o Voz do Cliente (ou VOC - Voice of Costumer).Ver Figs. 3 e 4 a seguir e Modelos no Anexo 1;

Mudanças: Mudança no conceito do processo ou projeto a partir de uma análise de custo benefício e aprovação; 
Recursos: Sempre haver a participação de um representante de cada área no grupo de melhoria e nas suas reuniões. Os membros alocados inicialmente ao projeto na fase do Pré-estudo foram confirmados na fase DEFINE.

Indicadores do Projeto: Não devem impactar os indicadores do negócio.

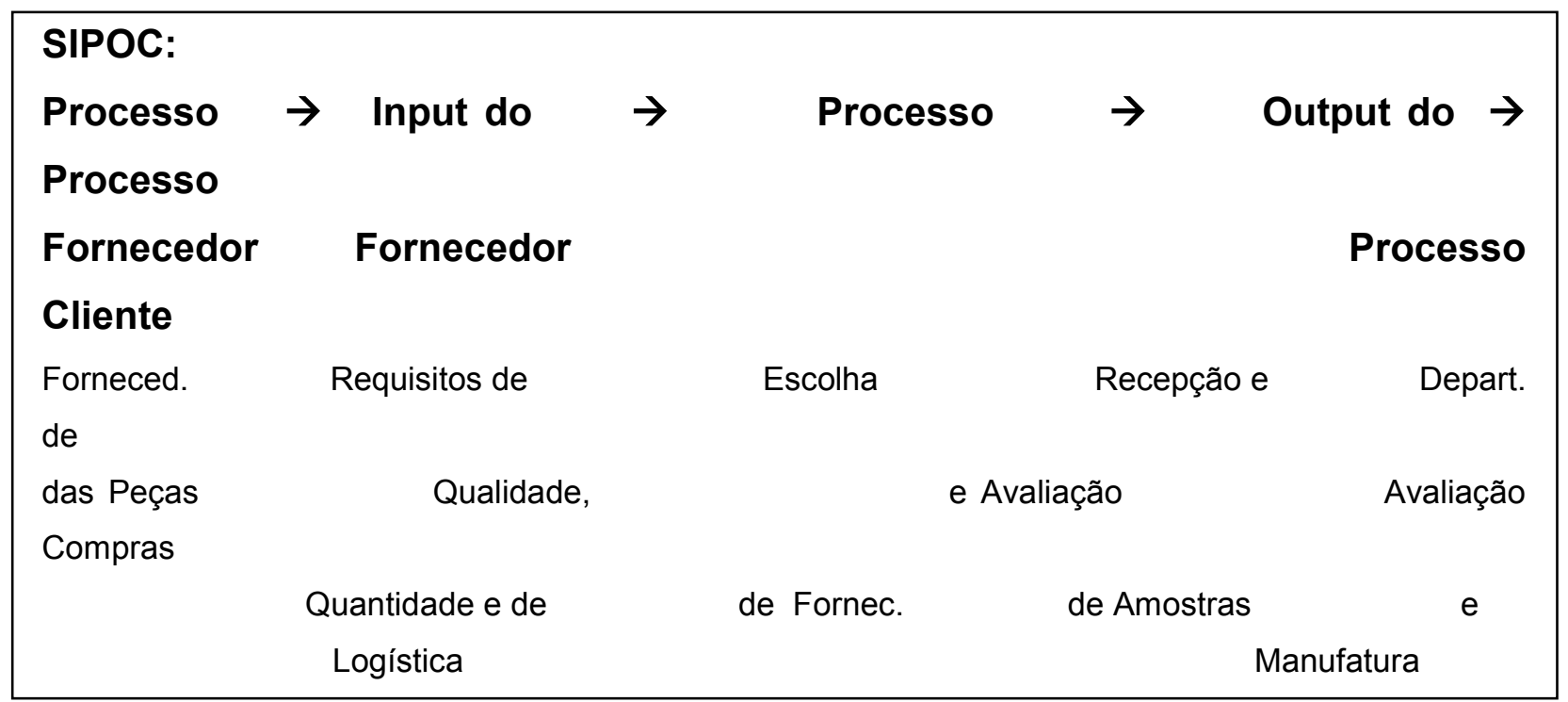

Figura 3: Exemplo de aplicação do Diagrama SIPOC ao processo em estudo.

\section{VOZ DO CLIENTE: REQUISITOS}

Satisfação do retrabalho

Cliente Final direta) garantia

\section{DIRECIONADORES}

Processo Produtivo

Itens de Qualidade

Qualidade Funcional das Peças

Montagem Final

\section{INDICADORES}

Produção sem

(entrega

Custos de

Figura 4: Exemplo de aplicação do Diagrama Voz do Cliente ao processo em estudo.

e) foi definido o calendário de atividades preliminar : A previsão estabelecida pelo Coordenador do Projeto e pelo Especialista no DMAIC para a duração das etapas foi: a) Pré-Estudo: elaborado anteriormente ao início oficial do projeto: 2 meses; b) Define: 1 mês; c) Measure: 3 meses; d) Analyse: 5 meses; e) Improve: 2 meses; f) Control: 1 mês. 
f) foi definida a classe do projeto como de pequeno porte. Ao ser feita em 17 de Abril de 2008 a Auditoria para a passagem à fase do MEASURE, foram apontadas pelo Auditor as seguintes pendências:

a) necessidade de confirmar a disponibilidade de recursos para assegurar a realização da fase MEASURE de acordo com o calendário de ações;

b) revisar os indicadores do Diagrama Voz do Cliente;

c) marcar reunião para validar os benefícios financeiros.

Tais pendências impossibilitaram a passagem do projeto para a fase seguinte até estas serem resolvidas, o que ocorreu em 19 de Maio de 2008.

As entregas listadas inicialmente (fase do Pré-estudo) foram traduzidas em objetivos medidos objetivamente através dos cinco indicadores definidos anteriormente e apresentados no CONTRATO.

\subsection{Fase Measure}

Nesta etapa foram desenvolvidos três mapas do fluxo de valor, uma vez que os problemas existentes passam por várias áreas da Empresa A. Foi utilizada como base a metodologia de Mapeamento do Fluxo de Valor. Foram eles:

a) Mapeamento do Processo de Nacionalização de Peças, com o objetivo de identificar-se cada uma das etapas necessárias a serem percorridas quando uma peça é nacionalizada;

b) Mapeamento do Processo de Manufatura das Peças na Empresa A, com o objetivo de conhecer-se com detalhes o processo industrial, uma vez que este é similar ao realizado no fornecedor (Empresa B);

C) Mapeamento do Processo de Compras.

Nesta etapa foram identificadas as peças que apresentavam os maiores problemas conforme os cinco indicadores definidos na fase DEFINE. Utilizou-se o Diagrama de Paretto de modo a focar-se sobre o conjunto de peças representativo para o estudo. Verificou-se que 10 peças representavam $80 \%$ dos problemas de rejeição no período de Dez de 2007 a Março de 2008. O custo de re-trabalho sobre tais peças foi bastante elevado, demonstrando a necessidade urgente de solução do problema. 
Os benefícios financeiros da realização do projeto ficaram claros com 0 levantamento dos custos de re-trabalho pagos pela Empresa $\mathrm{A}$ até o início do projeto.

Os indicadores escolhidos no DEFINE mostraram no MEASURE com clareza a situação atual do fornecedor (Empresa B). Foi realizada nesta última etapa uma validação do sistema de medição dos indicadores utilizados. A maior parte destes, já fazem parte do sistema de informações da Empresa A, tendo sido, portanto, de fácil obtenção. Um deles, no entanto, o custo de re-trabalho, exigiu um maior esforço, uma vez que as informações não estavam disponíveis no sistema no nível de detalhamento desejado. Um profissional da área de custos da Empresa A participou também desta avaliação, garantindo para o projeto a utilização da forma oficial de custeio utilizada na Empresa A e garantindo robustez aos custos obtidos. Foram também identificadas algumas oportunidades de melhorias rápidas, as quais foram analisadas com maior profundidade na etapa seguinte. A etapa do Measure encerrou-se em 15/07/08.

\subsection{Fase Analyse:}

A realização das atividades de brainstorming foram freqüentes nas reuniões do grupo do projeto, em função deste contar com representantes das várias áreas envolvidas. No entanto, em vários momentos foram convidados profissionais de outras áreas da Empresa $\mathrm{A}$ (tais como da área de Custos, de Manufatura, de Processos Industriais e Administrativos Específicos) a fim de investigarem-se determinadas hipóteses e utilizarem-se informações mais precisas ou completas, elevando-se o nível das discussões e eliminando-se dúvidas dos membros do projeto.

As atividades de benchmarking (investigação das melhores práticas) foram realizadas através dos profissionais envolvidos no projeto. Foram utilizadas as próprias empresas do grupo a que pertence a Empresa A para compararem-se os processos industriais e administrativos. Não foi possível realizar-se uma visita direcionada no Fornecedor B por parte do grupo do projeto em virtude da piora do relacionamento entre a Empresa $\mathrm{A}$ e o Fornecedor $\mathrm{B}$. Em virtude de não haver outro fornecedor das peças em questão no Brasil, não foram contatadas outras empresas. 
Foi identificada como possível causa das dificuldades da Empresa A em relação ao primeiro e terceiro processos descritos nos mapas ("a" e "c" citados na fase Measure) a existência de dois procedimentos internos para a condução do processo de nacionalização de peças, o qual envolve a atividade (e o Setor) de Compras, entre outras. Um destes procedimentos é o padrão da atividade e é utilizado na maior parte da nacionalização das peças. O outro é um procedimento simplificado, que possibilita uma redução do tempo de introdução da peça no país. $O$ primeiro envolve um maior número de áreas e fóruns para tomada de decisão e liberação das peças. Em função disto, é mais consistente, isto é, reduz as chances de problemas futuros, tais como a aprovação de um fornecedor sem os requisitos mínimos para tornar-se fornecedor da Empresa A. O segundo, envolve um número menor de áreas (as mais relevantes) e uma menor exigência de testes do processo e sua estabilidade. Traz a vantagem de ser um processo mais rápido e mais adequado às necessidades urgentes presentes nas operações da empresas atualmente. No entanto, o risco de apresentar problemas futuros é maior.

A fim de aprofundar-se a análise buscou-se informações organizacionais (registros) que deixassem claro como ocorreu o processo de nacionalização de tais peças, se tinha seguido o padrão da Empresa $A$ ou as exigências globais da corporação a que a Empresa A pertence. Houve dificuldade em se obter informações históricas a respeito das peças em virtude de todas serem originárias de projetos desenvolvidos no exterior e muitos deles, há mais de 5 anos. No entanto, foi elaborado um trabalho exaustivo de coleta de informações a respeito dos principais processos abordados no projeto, conseguindo-se uma visão mais clara dos níveis atuais e desejados dos indicadores definidos na fase Measure. Em relação ao processo de nacionalização verificou-se que a maior parte das peças que apresentou problemas não tinha seguido 0 procedimento completo de nacionalização existente na Empresa $A$, mas sim, o procedimento simplificado.

O processo descrito como item "b" na fase Measure não apresentou maiores problemas para ser investigado e analisado, uma vez que é executado pela Empresa $A$ há tempos e sobre o qual esta tem um bom controle. Muitos dos problemas enfrentados neste processo foram provenientes de peças recebidas com a qualidade insuficiente do Fornecedor $B$, as quais ainda teriam um processo industrial de transformação. 
Alguns Kaizens Rápidos foram desenvolvidos nesta fase. Estes foram conduzidos através do método PDCA (Plan-Do-Check-Action). São eles:

1) PDCA 1, focando o processo de aprovação de peças, analisando-se a utilização de um procedimento interno mais completo e outro mais simplificado (ambos já existentes).

2) PDCA 2, focando o processo de comunicação entre áreas internas da empresa, analisando-se a possibilidade de modificação do processo atual (sem envolvimento de todas as áreas de interesse - 04 áreas da Empresa A) para um processo ideal (com envolvimento de todas as áreas interessadas 09 áreas da Empresa $A$ ).

3) PDCA 3, focando o elevado índice de rejeição de peças, tanto internas como entregues por terceiros, analisando-se suas causas potenciais (seus processos industriais e logísticos) e a forma de eliminá-las.

4) PDCA 4, focando a processo de armazenagem de peças recebidas do fornecedor e em processamento na Empresa A, analisando-se a possibilidade de alteração do local e tipo de embalagens utilizadas, objetivando-se eliminar o sucateamento de peças.

$\mathrm{Na}$ primeira auditoria para conclusão da fase ANALYSE (07/08/2008) o auditor não autorizou a passagem à próxima etapa, em função de algumas pendências:

a) A garantia de recursos para o andamento do projeto;

b) Revisão dos PDCA's, com um maior foco na análise dos processos (internos e externos) e listando-se objetivamente as ações necessárias paras as mudanças.

Após isto, o auditor aprovou a passagem de etapa (em 02/09/08).

Com estas atividades de investigação, discussão e análise do Estado Atual e Futuro dos principais processos ("a","b" e "c" do item 4.5) abordados, obteve-se a revisão e atualização do CONTRATO. 


\subsection{Fase Improve:}

\subsubsection{Sub-fase de Decisão:}

A fim de verificar-se a eficácia dos kaizens rápidos (PDCA's) desenvolvidos foram executadas as seguintes ações:

\section{PDCA 1:}

a) entendimento detalhado dos dois procedimentos internos para aprovação de peças existentes; b) realização de análise comparativa entre ambos baseada nos seus pontos fortes e fracos e nas ameaças e oportunidades envolvidas; c) proposta de uma nova forma de trabalho (metodologia ou procedimento interno);

PDCA 2:

a) promover um work-shop com todas as pessoas envolvidas; b) assegurar com a nova metodologia que todos os departamentos afetados sejam informados das ações em andamento;

PDCA 3:

a) monitoramento e feed-back dos indicadores de produção (rejeição, sucata, peças produzidas) em cada turno; auditorias de qualidade diárias em dois veículos e a definição de um plano de ação se algum problema for detectado; b) projeto de novos meios de transporte de peças na pintura a fim de reduzir o risco de sofrerem danos;

PDCA 4:

a) novo arranjo físico e da embalagem para armazenar peças com problemas.

Dos 4 PDCA's apresentados, aprofundou-se o PDCA 1, que passou a receber o foco da atenção no projeto. Este passou a ser descrito da seguinte forma: Construção de uma nova metodologia, operacionalizada através de um procedimento interno, que contemple todos os requisitos necessários e suficientes para garantir um processo de aprovação de peças robusto, flexível e com o envolvimento das áreas afetadas. 
Em seguida, para avançar na implementação do PDCA 1, o Grupo de Trabalho fez as seguintes recomendações à Diretoria:

1) realizar um projeto piloto oficial para a aprovação de peças a fim de testar-se a nova metodologia, assegurando que todas as fases propostas serão seguidas;

2) propor um processo ideal para homologação de fornecedores, tendo como benchmark o antigo fornecedor da Empresa A localizado na Europa; visandose entender os parâmetros do processo, suas inspeções, os testes realizados para aprovação de amostras, os indicadores de rejeição e sucatas, o conceito e projeto dos moldes, etc.;

3) desenvolver uma melhor convergência dos indicadores da Empresa A.

\subsubsection{Sub-fase de Implantação:}

SITUAÇÃO DAS RECOMENDAÇÕES (Aprovação pela Diretoria):

* Recomendação 1: aprovada; desenvolver o novo procedimento e executar o piloto para qualquer tipo de peça e qualquer processo de aprovação; * Recomendação 2: não aprovada; * Recomendação 3: aprovada, propor um novo projeto com um time de trabalho. Tal projeto já estava em andamento liderado por outro grupo na Empresa A. Por isto, foi abandonado pelo Grupo de Trabalho;

Portanto, para a implantação da RECOMENDAÇÃO 1 desenvolveu-se uma Ficha Eletrônica, apresentada na Fig. 5 abaixo. Esta foi desenvolvida com o objetivo de se implantar a nova metodologia nos processos de nacionalização de peças na Empresa A. É emitida, ou origina-se a partir do comprador responsável pela peça. 


\section{Emitente - Comprador}

\begin{tabular}{|l|l|l|}
\hline Departamento: & Identificação na Empresa A: & Nome: \\
\hline Gerente: & Fone: & E-mail: \\
\hline
\end{tabular}

Dados da Peça e do Fornecedor

\begin{tabular}{|l|l|l|}
\hline Número da Peça & Edição: & Descrição da Peça: \\
\hline Fornecedor Atual (Código): & Classificação: & Nome: \\
\hline $\begin{array}{l}\text { Novo Fornecedor (Código): } \\
\begin{array}{l}\text { Redução de Custos? ( ) Sim ( ) } \\
\text { Não }\end{array}\end{array}$ & Razão: & Nome: \\
\hline
\end{tabular}

Check-List:

\begin{tabular}{|l|l|l|}
\hline ITEM & SIM & NÃO \\
\hline O novo fornecedor apresenta riscos comerciais, de qualidade ou financeiros ? & & \\
\hline O número da peça necessita ser mudado para alcançar-se rastreabilidade ? & & \\
\hline Mudanças no desenho da peça são necessárias ? & & \\
\hline Teste de validação na Empresa A são necessários ? & & \\
\hline Há necessidade de investimentos em ferramentas ? & & \\
\hline Mudança de peças planejada ou em andamento ? & & \\
\hline Mudanças no processo de manufatura da Empresa A são necessários ? & & \\
\hline Regras de Ouro da Logística da Empresa A estão sendo respeitadas ? & & \\
\hline Peça em questão está de acordo com o desenho ? & & \\
\hline Questionário de Avaliação respondido pelo Fornecedor ? & & \\
\hline Observações: & & \\
\hline Situação: & & \\
\hline
\end{tabular}

Figura 5 - Ficha Eletrônica para o Processo de Nacionalização na Empresa A

Esta Ficha ainda não foi testada em um caso prático em função de não ter havido o processo de nacionalização para nenhuma peça relevante dos veículos da Empresa A. No entanto, está pronta para ser aplicada e avaliada pelos profissionais que participaram de seu desenvolvimento e das áreas afetadas. A etapa Improve encerrou-se em 20/12/08.

\subsection{Fase Control:}

Até o final dos 12 meses de existência deste projeto, não havia sido realizada a avaliação da metodologia proposta através da aplicação da Ficha Eletrônica em peça ou componente a ser nacionalizado. 
No âmbito de todo o projeto, no entanto, foram utilizadas diversas ferramentas ou técnicas de controle. Apresenta-se aqui os 10 métodos ou ferramentas mais utilizados em trabalhos com o DMAIC por ANDRIETTA \& MIGUEL (2007) para uma comparação com o Estudo de Caso deste artigo.

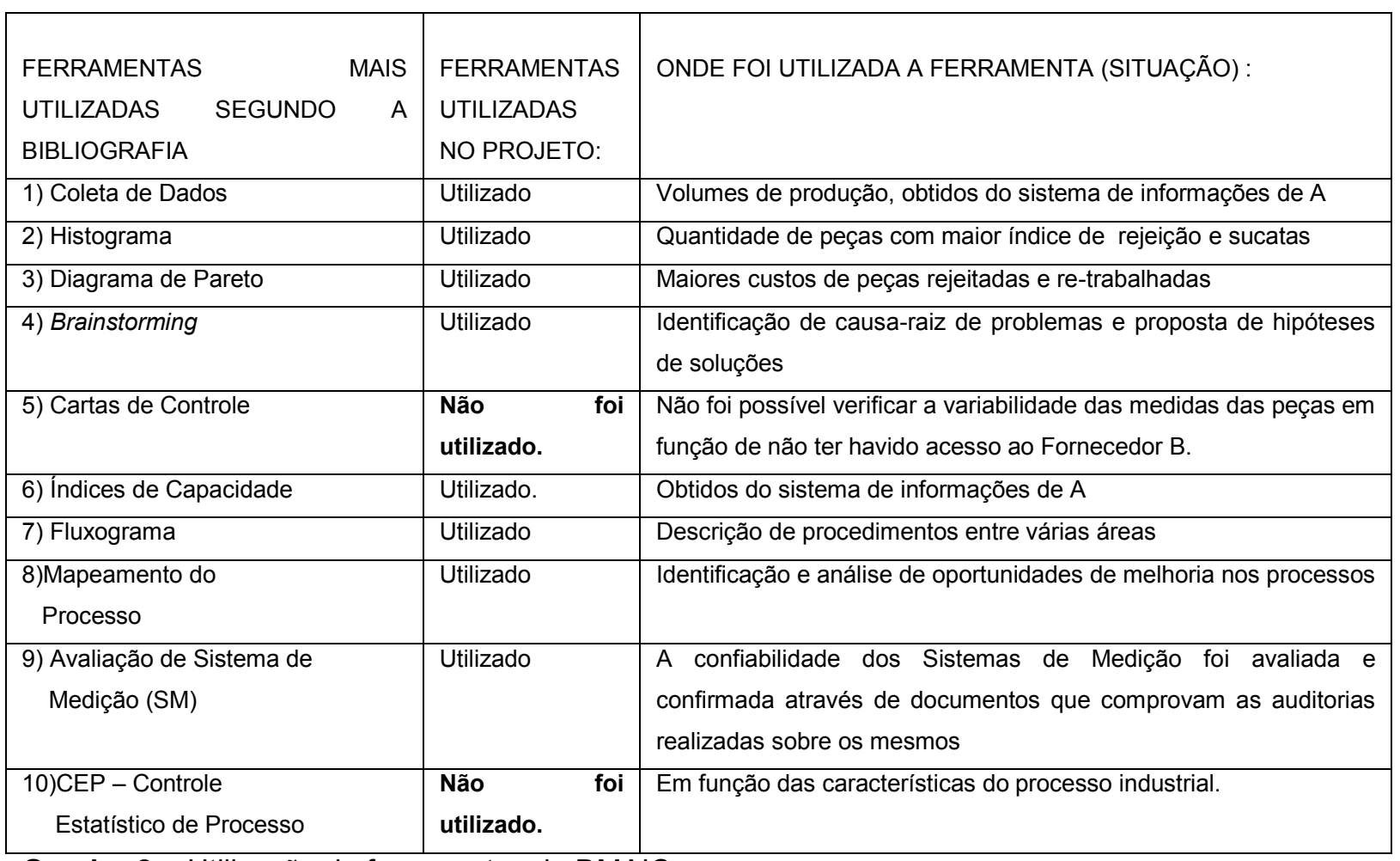

Quadro 2 - Utilização de ferramentas do DMAIC.

Verifica-se, com base no Quadro 2, que também no Estudo de Caso em questão, utilizaram-se as mesmas ferramentas (8 entre 10) consideradas as mais utilizadas em trabalhos em que o DMAIC é adotado.

O Quadro 3 a seguir ilustra como encerrou-se o projeto em termos de duração das etapas e sua consecução. Analisando-se seus dados, verifica-se que houve um atraso grande da etapa Define. Este ocorreu em virtude da dificuldade inicial para o projeto deslanchar, isto é, ser percebido como relevante para os públicos envolvidos. Outra causa possível foi a grande amplitude do projeto, que envolveu várias áreas da organização e as diferentes visões a respeito dos problemas enfrentados e a sua forma de solução. O atraso, no entanto, foi recuperado nas etapas seguintes, principalmente na etapa Analyse. 


\begin{tabular}{|c|c|c|c|}
\hline Etapa & $\begin{array}{c}\text { Duração Prevista } \\
\text { (mês) }\end{array}$ & $\begin{array}{c}\text { Duração Real } \\
\text { (mês) }\end{array}$ & Situação \\
\hline $\begin{array}{c}\text { Pré- } \\
\text { Estudo }\end{array}$ & dois & dois & $\begin{array}{c}\text { Concluída } \\
\text { Integralmente }\end{array}$ \\
\hline \hline Define & um & quatro & $\begin{array}{c}\text { Concluída } \\
\text { Integralmente }\end{array}$ \\
\hline \hline Measure & três & três & $\begin{array}{c}\text { Concluída } \\
\text { Integralmente }\end{array}$ \\
\hline Analyse & cinco & dois & $\begin{array}{c}\text { Concluída } \\
\text { Integralmente }\end{array}$ \\
\hline \hline Improve & & & dois \\
\hline Control & dois & um & Concluída Parcialmente \\
\hline
\end{tabular}

Quadro 3 - Evolução Prevista e Real das Etapas do Projeto

\section{CONCLUSÕES}

Como conclusões deste trabalho tem-se:

a) o método DMAIC para gestão de projetos interdisciplinares em uma organização de grande porte mostrou-se de grande valia para a obtenção de resultados confiáveis;

b) o método DMAIC possibilitou uma abordagem ampla, flexível e aprofundada do problema, bem como a integração dos profissionais das diversas áreas envolvidas em um grupo de trabalho;

c) a adoção do método DMAIC possibilitou à Empresa $\mathrm{A}$ um nível mais elevado de conhecimento dos processos envolvidos na nacionalização de peças;

d) a existência de profissional capacitado (habilidades técnicas e pessoais) para orientar o grupo no andamento dos trabalhos é um diferencial para o sucesso do projeto que adota o método DMAIC, pois é comum o grupo nas suas discussões desviar-se do foco do trabalho, o qual deve ser reconduzido ao assunto principal com bom senso e equilíbrio; 
e) a existência de um clima de companheirismo no grupo de trabalho, bem como de auditorias externas ao projeto, contribuíram significativamente para 0 sucesso deste;

f) o suporte e envolvimento da diretoria na avaliação das propostas geradas pelo Grupo de Trabalho mostrou-se fundamental para seu sucesso através do direcionamento para os pontos mais importantes;

g) mesmo não tendo sido realizado o Projeto Piloto na etapa Improve, a instalação do projeto levou a uma mudança de postura do fornecedor da Empresa A.

\section{REFERÊNCIAS:}

ANDRIETTA, J.M.; MIGUEL,P.A.C. Aplicação do programa seis sigma no Brasil: resultados de um levantamento tipo survey exploratório-descritivo e perspectivas para pesquisas futuras. Gestão da Produção. São Carlos, v.14, n.2, p. 203-219, maio-ago, 2007.

BAÑUELAS, R.; ANTONY, J. Critical success factors for the successful implementation of six sigma projects in organizations. The TQM Magazine,v.14, n.2, p.92-99, 2002.

CAMPOS, V. F. TQC: Controle de qualidade total (no estilo japonês). Belo Horizonte, MG: Fundação Christiano Ottoni, Escola de Eng. da UFMG, 1992.

CARVALHO, M.M.; HO, L. L.; PINTO, S.H.B. Main quality programs characteristics in large size Brazilian companies. International Journal of Quality \& Reliability Management. Vol. 25, No. 3, 2008, p. 276-291.

FERNANDES, M.M.; TURRIONI, J.B. Seleção de projetos Seis Sigma: aplicação em uma indústria do setor automobilístico. Produção, v.17, n.3, p 579-591, set./dez. 2007.

FRANZ , L.A. S.; TEN CATEN, C.S. Uma discussão quanto à relação entre os métodos DMAIC e PDCA. SEMANA DE ENGENHARIA DE PRODUÇÃO E TRANSPORTES, 3. 2003. Anais.. Porto Alegre: UFRGS, 2003.

GUPTA, P. Innovation: the key to a successful project. Six Sigma Forum Magazine, v.4, n.4, p.13-17, 2005.

KUMAR,S.; SOSNOSKI,M. Using DMAIC six sigma to systematically improve shopfloor production quality and costs. International Journal of Productivity and Performance Management, v.58, n. 3, 2009. 
LAKATOS, E. M.; MARCONI, M.A Fundamentos de metodologia científica. 6 ed. São Paulo: Atlas, 2009.

LYNCH, D. P.; BERTOLINO, S.; CLOUTIER,E. How to scope DMAIC projects: the importance of the right objective cannot be overestimated. Quality Progress. January, 2003.

PARIS, W. S. Metodologia para identificação de causa raiz e solução de problemas complexos em processos industriais: um estudo de caso. Dissertação (Mestrado) - Programa de Pós-Graduação em Eng. Mecânica. Universidade Federal do Paraná. Curitiba, 2003.

SENAPATI,S.R. Six Sigma: myths and realities. International Journal of Quality \& Reliability Management, v.21, n. 6, p 683-690, 2004.

SHOOK, J.; ROTHER, M. Aprendendo a enxergar: mapeando o fluxo de valor para agregar valor e eliminar o desperdício. São Paulo: Lean Institute Brasil, 1998.

WERKEMA, M.C.C. Criando a cultura seis sigma. Rio de Janeiro. Qualitymark, v. 1, 2002.

YIN, R. K. Estudo de caso: planejamento e métodos. 3 ed. Porto Alegre: Bookman, 2005.

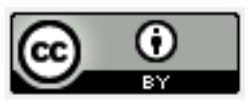


ANEXO 1 - Modelos de Documentos: CONTRATO, SIPOC E VOC.

\begin{tabular}{|l|l|}
\hline \multicolumn{2}{|l|}{ CONTRATO } \\
NOME DO PROJETO:
\end{tabular}

SIPOC (Supply-Input-Process-Output-Customer)

\begin{tabular}{|l|l|l|l|l|}
\hline \hline $\begin{array}{l}\text { Processo } \\
\text { Fornecedor: }\end{array}$ & $\begin{array}{l}\text { Entrada do } \\
\text { Fornecedor: }\end{array}$ & $\begin{array}{l}\text { Processo em } \\
\text { Estudo: }\end{array}$ & $\begin{array}{l}\text { Saída do } \\
\text { Processo: }\end{array}$ & $\begin{array}{l}\text { Processo } \\
\text { Cliente: }\end{array}$ \\
\hline \hline & & & & \\
\hline
\end{tabular}

\begin{tabular}{|l|l|l|}
\hline \multicolumn{2}{|l|}{ VOC - Voice of Customer } \\
\hline \hline Requisitos: & Direcionadores: & Indicadores: \\
\hline \hline & & \\
& & \\
\hline
\end{tabular}

